\title{
Anti-adipogenic effects of the traditional herbal formula Dohongsamul-tang in 3T3-L1 adipocytes
}

\author{
Eun Hyoung Shim, Hoyoung Lee ${ }^{1}$, Myeong Soo Lee ${ }^{2}$ and Sooseong You ${ }^{1 *}$
}

\begin{abstract}
Background: Blood stasis syndrome (BSS) is a general pattern identification and refers to pathological stagnation of blood circulation, dysfunction of endothelial cells or metabolic disorder in traditional Korean medicine (TKM). Dohongsamul-Tang (DHSMT) is a well-known traditional herbal formula which used for treatment and prevention of BSS by promoting blood circulation in TKM.

Methods: Cytotoxicity of DHSMT was examined by cell counting kit-8 (CCK-8). We also investigated the anti-adipogenesis effect of DHSMT by using Oil Red O staining, intracellular triglyceride assay leptin ELISA and western blot analysis in 3T3-L1 adipocytes. In addition, the accumulation of adiponectin, resistin and plasminogen activator inhibitor-1 (PAI-1) were measured by magnetic bead panel kit.

Results: Oil Red O staining showed that DHSMT markedly reduced fat accumulation without affecting cell cytotoxicity. DHSMT also significantly decreased accumulation of triglyceride and adipokines such as leptin, adiponectin, resistin and PAl-1 compared with fully differentiated adipocytes. Furthermore, our results found that DHSMT significantly suppressed the adipocyte differentiation by downregulating adipogenic-specific transcriptional factors such as peroxisome proliferator-activated receptor gamma (PPARY), CCAAT/enhancer binding proteins alpha (C/EBPa) and fatty acid binding protein 4 (FABP4) in adipocytes.
\end{abstract}

Conclusions: Taken together, our findings provide that DHSMT has potential for treatment and prevention of obesity or MS related to BSS.

Keywords: Dohongsamul-tang, Blood stasis syndrome, Anti-adipogenesis, Metabolic syndrome, Herbal medicine

\section{Background}

Metabolic syndrome (MS) is accompanied with risk factors such as disorder of glucose metabolism, obesity, dyslipidemia, hyperglycemia, hypertension, diabetes mellitus or insulin resistance with two or more conditions occurring concurrently [1-3]. Obesity results from an imbalance between caloric intake and expenditure and is characterized by an increased risk of MS, including hypertension, cardiovascular disease, and type 2 diabetes [4]. Blood stasis syndrome (BSS) is an important pathological concept in traditional Korean medicine (TKM) that was first recorded in Huangdi's Inner

\footnotetext{
*Correspondence: ethink33@kiom.re.kr

${ }^{1}$ KM Fundamental Research Division, Korea Institute of Oriental Medicine 483

Expo-ro, Yuseong-gu, Daejeon 305-811, Republic of Korea

Full list of author information is available at the end of the article
}

Classic [5]. In recent years, several studies have reported that BSS is related to MS and its risk factors such as obesity, atherosclerosis, hypertension and diabetes mellitus [6-8]. Several herbal formulas such as Dohongsamul-Tang (DHSMT), Doinseunggi-Tang, Sobokchukeo-Tang, Hyeolbuchukeo-Tang have been widely used for treating BSS by circulating blood flow in TKM. Notably, DHSMT, which was first recorded in The Golden Mirror of Medicine, is a traditional herbal formula containing angelis gigantis radix, persicae semen, rehmanniae radix, cnidii rhizome, and carthami flos. And, DHSMT promotes blood circulation according to TKM and has been used to treat BSS, dysmenorrhea, contusion, abnormally colored menses, and menostasis [9]. To date, several studies have reported the effects of DHSMT, which include an anti-trombotic effect [10], an anti-inflammatory effect 
$[11,12]$, and relief from endometriosis [13]. However, the mechanism of action of DHSMT is still unclear. There are few studies available that explain the mechanism of action of DHSMT. Therefore, we evaluated its potential effects on anti-adipogenesis, regulation of transcription factors related to adipogenesis of 3T3-L1 adipocytes.

\section{Methods}

\section{Materials}

The mouse fibroblast cell line, 3T3-L1 cells were obtained from the American Type Culture Collection (ATCC, Manassas, VA, USA) and Dulbeco's modified eagle's medium (DMEM), fetal bovine serum (FBS), newborn calf serum (NBCS), penicillin-streptomycin (P\&S) and Dulbeco's phosphate-buffered saline (DPBS) were obtained from Gibco BRL. (NY, USA). Dimethyl sulfoxide (DMSO), formaldehyde, dexamethasone (DEX), 3-isobutyl-1-methylisobutylxanthine (IBMX), triton X-100 and Oil Red O staining powder were purchased from Sigma-Aldrich (St. Louis, MO, USA) and the cell counting kit-8 (CCK-8) was purchased from Dojindo Laboratories (Kumamoto, Japan). Trigliceride (TG) kit was obtained from Bioassay Systems (CA, USA) and leptin ELISA kit was purchased from R\&D System Inc. (MI, USA). Milliplex MAP mouse adipocyte magnetic bead panel kit was obtained from Millipore Co. (MA, USA). Antibodies against proliferator-activated receptor gamma (PPAR $\gamma$ ) and fatty acid binding protein 4 (FABP4) were purchased from Cell Signaling Technology Inc. (Beverly, MA, USA), CCAAT/enhancer binding proteins alpha $(\mathrm{C} / \mathrm{EBP} \alpha)$ and $\beta-$ actin were purchased from Santa Cruz Biotechnology Inc. (CA, USA). The anti-mouse or anti-rabbit secondary antibody attached to horseradish-peroxidase-conjugate were obtained from Bio-Rad Laboratories Inc. (PA, USA). All other reagents from commercial sources were condition of analytical grade.

\section{Preparation of herbal extracts}

DHSMT composed of each five different types of herbs including angelis gigantis radix, persicae semen, rehmanniae radix, cnidii rhizome, carthami flos (Table 1). Each herbs were obtained from from a traditional herb market, Omniherb (Daegu, Korea) in 2012 and medicinal herbs crushed by grinder were extracted by heating in distilled water for $3 \mathrm{~h}$ at $100{ }^{\circ} \mathrm{C}$ using reflux extraction (COSMOS-660, Kyungseo Machine Co. Incheon, Korea). After then, DHSMT was concentrated by using vacuum evaporator (EYELA N-12 EYEKA CA-1112, Tokyo, Japan) and was freeze-dried (PVTFD-100, ilShinBioBase, Gyeonggi-do, Korea). The herbal components were identified by Dr. Jun-Kyung Lee of Hyemin Dispensary of Oriental Medicine (Jeonju, Korea). The voucher specimen (BS-2) and each herbal components were stored at the Korea Medicine Fundamental Research Division, Korea Institute of Oriental Medicine (Daejeon, Korea).
Table 1 Prescription of Dohongsamul-Tang (DHSMT)

\begin{tabular}{|c|c|c|c|}
\hline \multicolumn{2}{|l|}{ Crude drug } & \multirow[t]{2}{*}{ Original region } & \multirow[t]{2}{*}{ Dosage (g) } \\
\hline Herbal name & Scientific name & & \\
\hline Angelis gigantis radix & $\begin{array}{l}\text { Angelica gigas } \\
\text { Nakai }\end{array}$ & Korea & 16.00 \\
\hline Persicae semen & $\begin{array}{l}\text { Prunus persica } \\
\text { Batsch }\end{array}$ & China & 16.00 \\
\hline Rehmanniae radix & $\begin{array}{l}\text { Rehmannia } \\
\text { glutinosa Libosch }\end{array}$ & Korea & 12.00 \\
\hline Cnidii rhizome & $\begin{array}{l}\text { Cnidium officinale } \\
\text { Makino }\end{array}$ & Korea & 8.00 \\
\hline Carthami flos & $\begin{array}{l}\text { Carthamus tinctorius } \\
\text { Linne }\end{array}$ & Korea & 8.00 \\
\hline Total (g) & & & 60.00 \\
\hline Yield (\%) & & & 14.81 \\
\hline
\end{tabular}

High performance liquid chromatography (HPLC) analysis The lyophilized extract $(10 \mathrm{mg})$ was dissolved in $70 \%$ methanol $(5 \mathrm{ml})$ and then filtered through a $0.2 \mu \mathrm{m}$ membrane filter (Woongki Science Co., Ltd., Seoul, Korea) before being injected into HPLC for component analysis. The purity of the ten standard compounds was $\geq 98.0 \%$ using HPLC analysis. The HPLC grade solvents, methanol, acetonitrile and water were obtained from J.T.Baker (Phillipsburg, NJ, USA). Trifluoroacetic acid (analytical reagent grade) and the standards were procured from Sigma-Aldrich (Merck Millipore, Darmstadt, Germany). The HPLC system consisted of a Waters Alliance 2695 system coupled with a 2998 photodiode array detector (Waters Corporation, Mitford, MA, USA). Data processing was performed with Empower software, version 3 (Waters Corporation, Milford, MA, USA). The 5 components in DHSMT were separated using a Luna $5 \mu \mathrm{m} \mathrm{C18} 100 \mathrm{~A}$ column $(4.6 \times 250 \mathrm{~mm}, 5 \mu \mathrm{m}$ particle size, no. 00G-4252-E0; Phenomenex, Inc., Torrance, CA, USA). The monitoring was performed at $330 \mathrm{~nm}$ and $400 \mathrm{~nm}$ for three compounds (nodakenin, ferulic acid and sophoricoside) and two compounds (safflomin A and quercetin), respectively. The mobile phases consisted of water with $0.1 \%(\mathrm{v} / \mathrm{v})$ trifluoroacetic acid (solvent A) and acetonitrile (solvent B) at a flow rate of $1.0 \mathrm{ml} / \mathrm{min}$. The gradient conditions changed as presented in Table 2 . The injection volume was $10 \mu \mathrm{l}$.

\section{Cell culture and differentiation}

The mouse fibroblast cell line, 3T3-L1 cells were cultured in DMEM containing 10\% NBCS and 1\% P\&S at $37{ }^{\circ} \mathrm{C}$ in a humidified atmosphere with $5 \% \mathrm{CO}_{2}$. For cell differentiation, 3T3-L1 cells were seeded in growth media to full confluence. After confluence, cells were replaced to differentiation medium: DMEM containing $10 \%$ FBS, $1 \%$ P\&S and a mixture of $0.5 \mathrm{mM}$ IBMX, 1 $\mathrm{uM}$ dexamethasone, $1 \mu \mathrm{g} / \mathrm{ml}$ insulin (MDI), and treated 
Table 2 Composition of mobile phase for chromatographic separation

\begin{tabular}{lll}
\hline Time $(\mathrm{min})$ & Solvent $^{\mathrm{a}}(\%)$ & Solvent $^{\mathrm{b}}(\%)$ \\
\hline 0 & 95 & 5 \\
30 & 40 & 60 \\
40 & 0 & 100 \\
45 & 0 & 100 \\
50 & 95 & 5 \\
60 & 95 & 5
\end{tabular}

${ }^{\mathrm{a}} 0.1 \%(\mathrm{v} / \mathrm{v})$ trifluoroacetic acid in water

bacetonitrile

with various concentration of DHSMT and $10 \mu \mathrm{M}$ of SB203580 used as a positive control for $48 \mathrm{~h}$ (from day 0 to day 2). At this time, the cells were changed with DMEM containing $1 \mu \mathrm{g} / \mathrm{ml}$ insulin but no IBMX or DEX and treated with various concentration of DHSMT and SB203580 for following $72 \mathrm{~h}$ (from day 2 to day 5). After then, the medium was replaced and treated with DHSMT and SB203580 for the following $48 \mathrm{~h}$ (from day 5 to day 7).

\section{Cell cytotoxicity}

The cell viability was examined by CCK-8. 3T3-L1 cells were seeded in 96-well plates and treated with various concentrations $(0,10,20,50,100,200,500$ and $1000 \mu \mathrm{g} /$ $\mathrm{mL}$ ) of DHSMT for $48 \mathrm{~h}$. The absorbance was measured at $450 \mathrm{~nm}$ using a Benchmark Plus microplate reader (Bio-Rad Laboratories Inc., CA, USA) and the percentages of cell viability were calculated.

\section{Oil red $\mathrm{O}$ staining and fat droplets quantification}

After cell differentiation, cells were stained with Oil Red O solution containing $0.3 \%$ Oil Red O in $60 \%$ isopropanol to measure fat droplets in adipocytes. Differentiated cells were washed with DPBS and fixed with $10 \%$ formalin for $1 \mathrm{~h}$ and stained with Oil Red $\mathrm{O}$ solution for $30 \mathrm{~min}$ at room temperature. After then, cells were washed three times with distilled water and visualized by microscopy (Olympus, Tokyo, Japan). To determine lipid accumulation, stained lipid droplets were dissolved in 100\% DMSO and quantified by measuring the optical absorbance at 530 nm using a Benchmark Plus microplate reader.

\section{TG, leptin and adipokines production on adipogenesis}

TG, leptin and adipokines production were measured after finishing cell differentiation in the presence or absence of DHSMT. Cell lysates were used to determine the TG (Bioassay Systems, CA, USA) quantification and supernatant was analyzed by according manufacturer's protocols for leptin immunoassay (R\&D System Inc., MI, USA). Adipokines production such as adiponectin, resistin and plasminogen activator inhibitor-1 (PAI-1) was measured using a Milliplex ${ }^{\bullet}$ MAP mouse adipocyte magnetic bead panel kit (MADCYMAG-72 K, Millipore Co. USA). Briefly, cultured supernatant was collected from the differentiated adipocytes which were treated in the presence or absence of DHSMT. Signal values were detected on a Bioplex $^{\odot} 200$ system and Bioplex pro II wash station (Luminex, xMAP ${ }^{\circledR}$ Technology, Texas, USA) by according manufacturer's protocols. Each samples were analyzed by the Bio-Plex 200 system and adipokine concentrations were calculated by using a standard curve.

\section{Western blot analysis}

Differentiated cells were washed twice with cold DPBS, harvested using a cell scraper and lysed with RIPA cell lysis buffer containing $0.5 \mathrm{M}$ Tris- $\mathrm{HCl}, \mathrm{pH} 7.4,1.5 \mathrm{M}$ $\mathrm{NaCl}, 2.5 \%$ deoxylcholic acid, 10\% NP-40, 10 mM EDTA. And then, cell lysates were centrifuged at 13,000 rpm for 15 min at $4{ }^{\circ} \mathrm{C}$. Protein concentration was measured with using the BCA protein assay kit (Thermo Fisher Scientific Inc., Rockford, IL, USA). Each proteins present in cell lysates were separated on 4-20\% Criterion ${ }^{\mathrm{Tm}}$ TGX $^{\mathrm{\tau m}}$ precast Gel (Bio-Rad Laboratories Inc., PA, USA) electrophoresis and transferred onto the polyvinylidene fluoride membrane (PVDF, Amersham Pharmacia Biotech, Little Chalfont, UK). The membrane was then blocked for $1 \mathrm{~h}$ at room temperature with 5\% skim milk and incubated with 1:1000 dilutions of each different primary antibodies for overnight at $4{ }^{\circ} \mathrm{C}$. After then, membrane was incubated with horseradish-peroxidase-conjugate anti-mouse or anti-rabbit secondary antibodies (1:3000 dilutions) for $1 \mathrm{~h}$ at room temperature, and immunoreactive proteins were detected with the ECL kit (Thermo scientific, Rockford, UK). Bands were visualized by using CemiDoc ${ }^{\mathrm{TM}} \mathrm{XRS}+$ image analyzer (Bio-Rad Laboratories Inc., PA, USA).

\section{Statistical analysis}

All data results are indicated as means \pm SEM and all determination were repeated triplicate. The one-way analysis of variance (ANOVA) by Bonferroni multiple comparison method (SYSTAT 13.0 SPSS Inc. U.S.A) was used to evaluate the difference among multiple group. The $p$-value $<0.05$ was considered statistically significant.

\section{Results}

Evaluation of the cytotoxic effects of DHSMT in 3T3-L1 cells

The yield of DHSMT was $14.81 \%(w / w)$ after freezedrying. We evaluated the possible cytotoxicity of DHSMT in 3T3-L1 cells by using the CCK-8 assay. The cells were treated with various concentrations of DHSMT $(0,10,20$, $50,100,200,500$ or $1000 \mu \mathrm{g} / \mathrm{mL})$. DHSMT has no significant cytotoxic effect in 3T3-L1 cells (Fig. 1). Therefore, further studies used a range of non-cytotoxic concentrations $(62.5,125,250$ and $500 \mu \mathrm{g} / \mathrm{mL})$. 


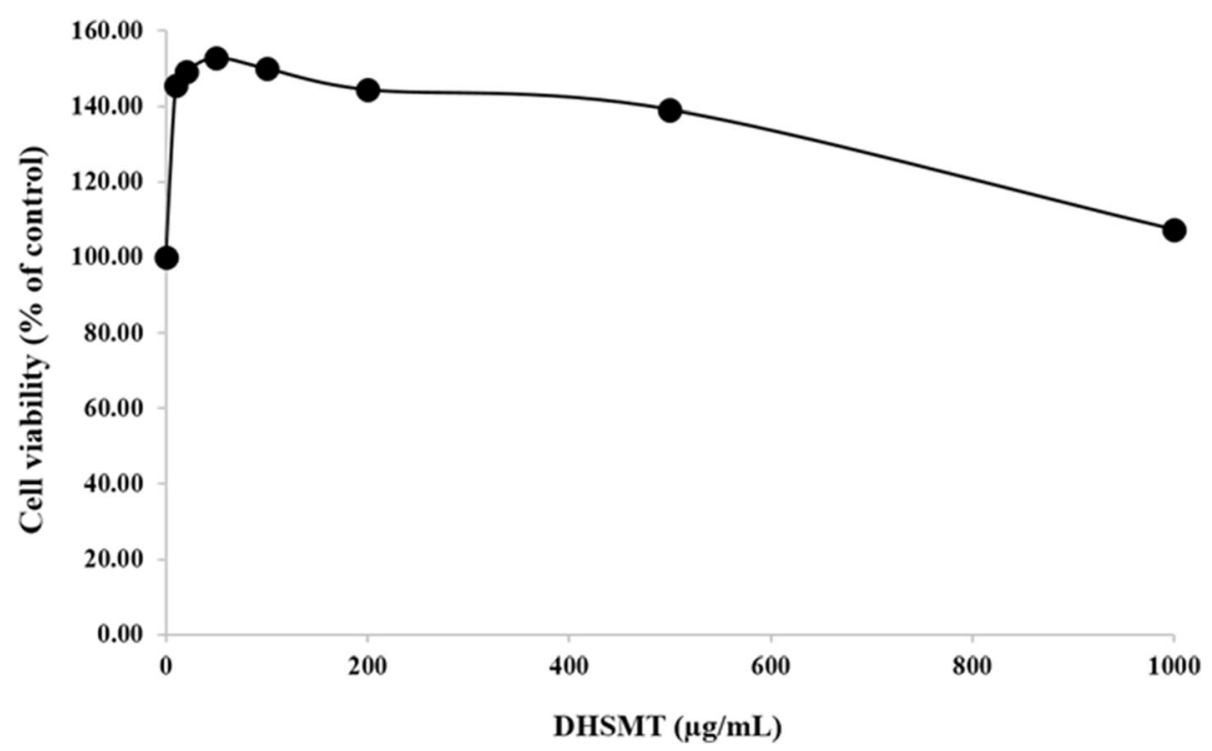

Fig. 1 Cytotoxic effects of DHSMT in 3T3-L1 cells. 3T3-L1 cells were treated with various concentrations of DHSMT (0, 10, 20, 50, 100, 200, 500 and $1000 \mathrm{\mu g} / \mathrm{mL}$ ) for $48 \mathrm{~h}$. Cell cytotoxicity was measured by using CCK-8 kit and the absorbance was measured at $450 \mathrm{~nm}$. The data are mean values of three experiments \pm SEM

\section{HPLC analysis of DHSMT}

The results were obtained using mobile phases consisting of $1.0 \%(\mathrm{v} / \mathrm{v})$ trifluoroacetic acid (solvent A) and acetonitrile with $1.0 \%(\mathrm{v} / \mathrm{v})$ trifluoroacetic acid (solvent B). Quantitation was achieved using photodiode array detection in the region 200-400 $\mathrm{nm}$ based on the retention times and UV spectra compared with the standards. The UV absorbance was recorded at $330 \mathrm{~nm}$ for three compounds and $400 \mathrm{~nm}$ for two compounds. The retention times of compounds were 21.09 (nodakenin), 21.34 (ferulic acid), 21.84 (sophoricoside), 15.31 (safflomic A) and 30.21(quercetin) min, respectively (Fig. 2).

\section{Effect of DHSMT on lipid and leptin accumulation in adipocytes}

To evaluate intracellular lipid accumulation in 3T3-L1 adipocytes, we performed Oil Red O staining. As shown in Fig. 3a, fat droplets significantly increased after differentiation for 7 days. However, fat droplets in cells treated by

a

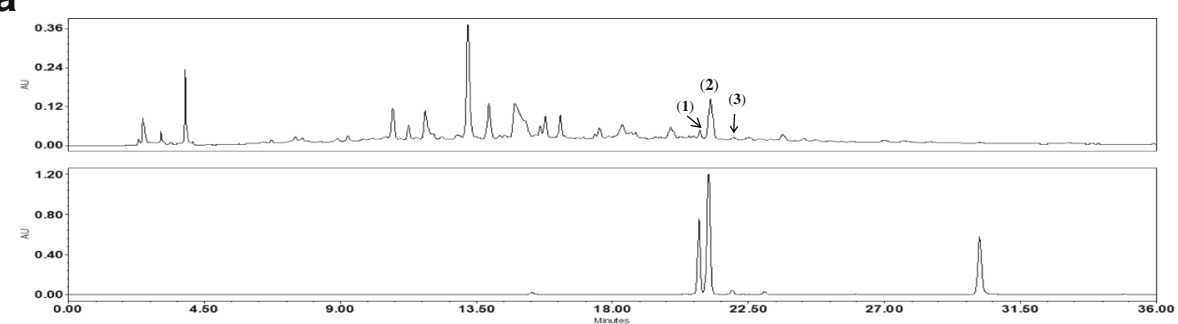

b.

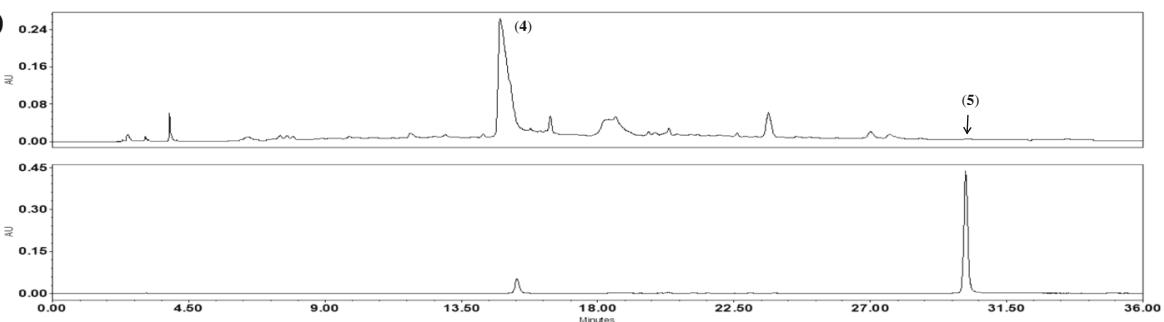

Fig. 2 HPLC chromatogram standard mixture and DHSMT. a $330 \mathrm{~nm}$ and b $400 \mathrm{~nm}$. (1) nodakenin, (2) ferulic acid, (3) sophoricoside, (4) safflomin $A$, and (5) quercetin 
a
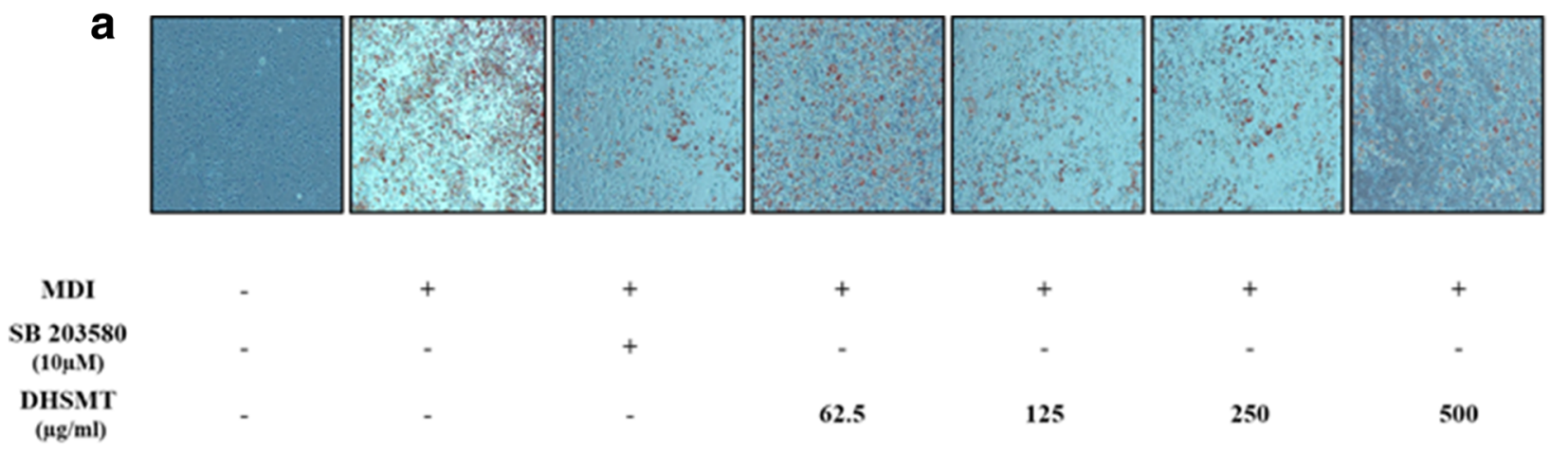

b

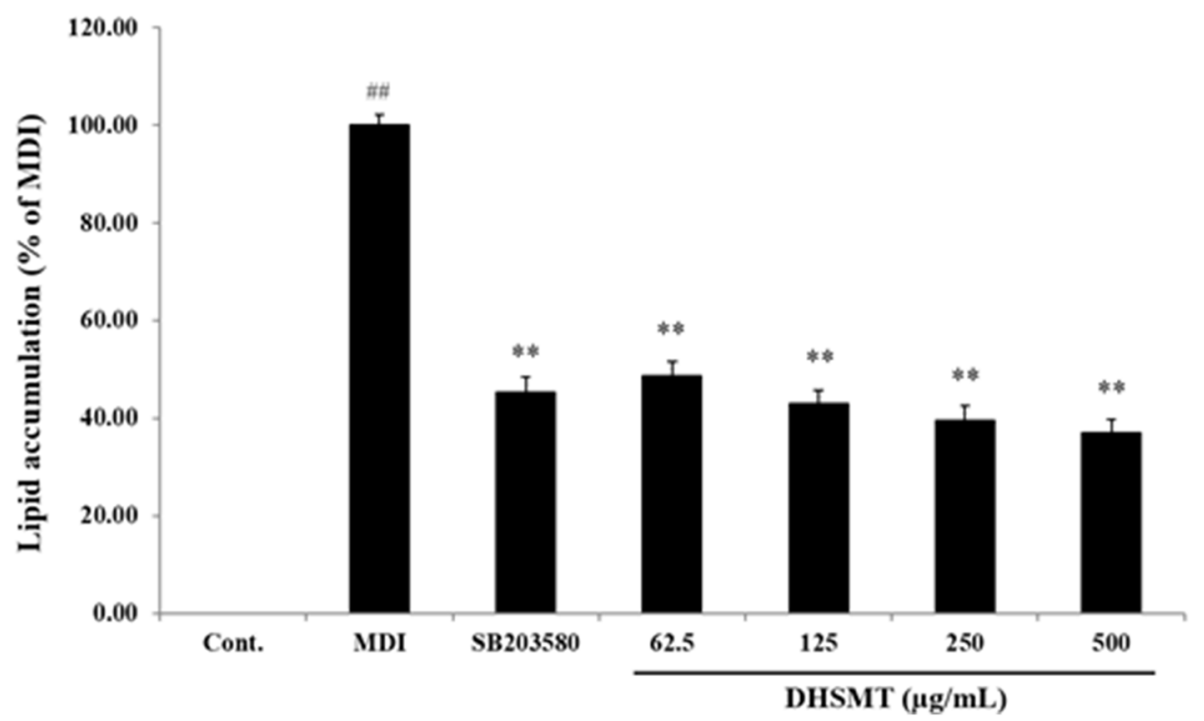

Fig. 3 Inhibitory effect of DHSMT on the lipid accumulation in 3T3-L1 adipocytes during adipogenesis. 3T3-L1 cells were differentiated into adipocytes by incubation with a mixture of 3-isobutyl-1-methylisobutylxanthine, dexamethasone and insulin (MDI) and exposed to various concentrations of $\operatorname{DHSMT}(0,62.5,125,250$ and $500 \mu \mathrm{g} / \mathrm{ml})$ and SB203580 for 7 days. a Lipid accumulation in cells were evaluated by Oil red $O$ staining and visualized using microscope at $\times 100$ of magnification. $\mathbf{b}$ Stained lipid droplet was dissolved in DMSO and quantified by reading the absorbance at $530 \mathrm{~nm}$. The data are mean values of three experiments \pm SEM; \#\#<0.01 compared with control, ${ }^{*} P<0.05$; **P $<0.01$ compared with the $\mathrm{MDI}$

DHSMT and SB203580 decreased compared with the fully differentiated adipocytes. SB203580 is a selective inhibitor of p38 MAPK. This compound suppresses early adipogenesis by inhibiting the activation of p38 MAPK involved in adipocyte differentiation $[14,15]$. In the present study, we used SB203580 as a positive control to confirm the efficacy on adipocyte differentiation of DHSMT. To quantify the lipid accumulation, fat droplets were dissolved by DMSO. Similar to Oil Red O staining, DHSMT significantly suppressed the lipid accumulation in a dose-dependently manner ( $p<0.01$ vs. MDI; Fig. 3b). Moreover, these results are consistent with the results that the TG content of cells in the presence or absence of DHSMT decreased $42.39 \pm$ $2.78 \%(62.5 \mu \mathrm{g} / \mathrm{mL}), 57.09 \pm 5.22 \%(125 \mu \mathrm{g} / \mathrm{mL}), 55.66 \pm$ $3.67 \%(250 \mu \mathrm{g} / \mathrm{mL})$ and $61.25 \pm 5.63 \%(500 \mu \mathrm{g} / \mathrm{mL})(p<0.01$ vs. MDI; Fig. 4a). DHSMT also significantly reduced leptin production $\quad(68.26 \pm 2.99 \% \quad(62.5 \mu \mathrm{g} / \mathrm{mL}), \quad 65.27 \pm 2.74 \%$ $(125 \mu \mathrm{g} / \mathrm{mL}), 73.05 \pm 0.60 \%(250 \mu \mathrm{g} / \mathrm{mL})$ and $79.64 \pm$ $1.04 \%(500 \mu \mathrm{g} / \mathrm{mL}))$ compared with fully differentiated cells ( $p<0.01$ vs. MDI; Fig. $4 \mathrm{~b})$. The positive control, SB203580, dramatically inhibited adipogenesis in 3T3L1 cells $(p<0.01$ vs. MDI).

\section{Effect of DHSMT on the formation of adipokines in adipocytes}

To determine the effect of DHSMT on the formation of adipokines in fully differentiated adipocytes, we performed the multiplex assay for adiponectin, resistin and PAI-1 by using the supernatant. As shown in Fig. 5, DHSMT significantly decreased the levels of adiponectin. The concentrations of adiponectin were $430.25 \pm 9.60 \mu \mathrm{g} /$ $\mathrm{mL}, \quad 360.75 \pm 32.96 \mu \mathrm{g} / \mathrm{mL}, \quad 396.42 \pm 32.61 \mu \mathrm{g} / \mathrm{mL}$ and 

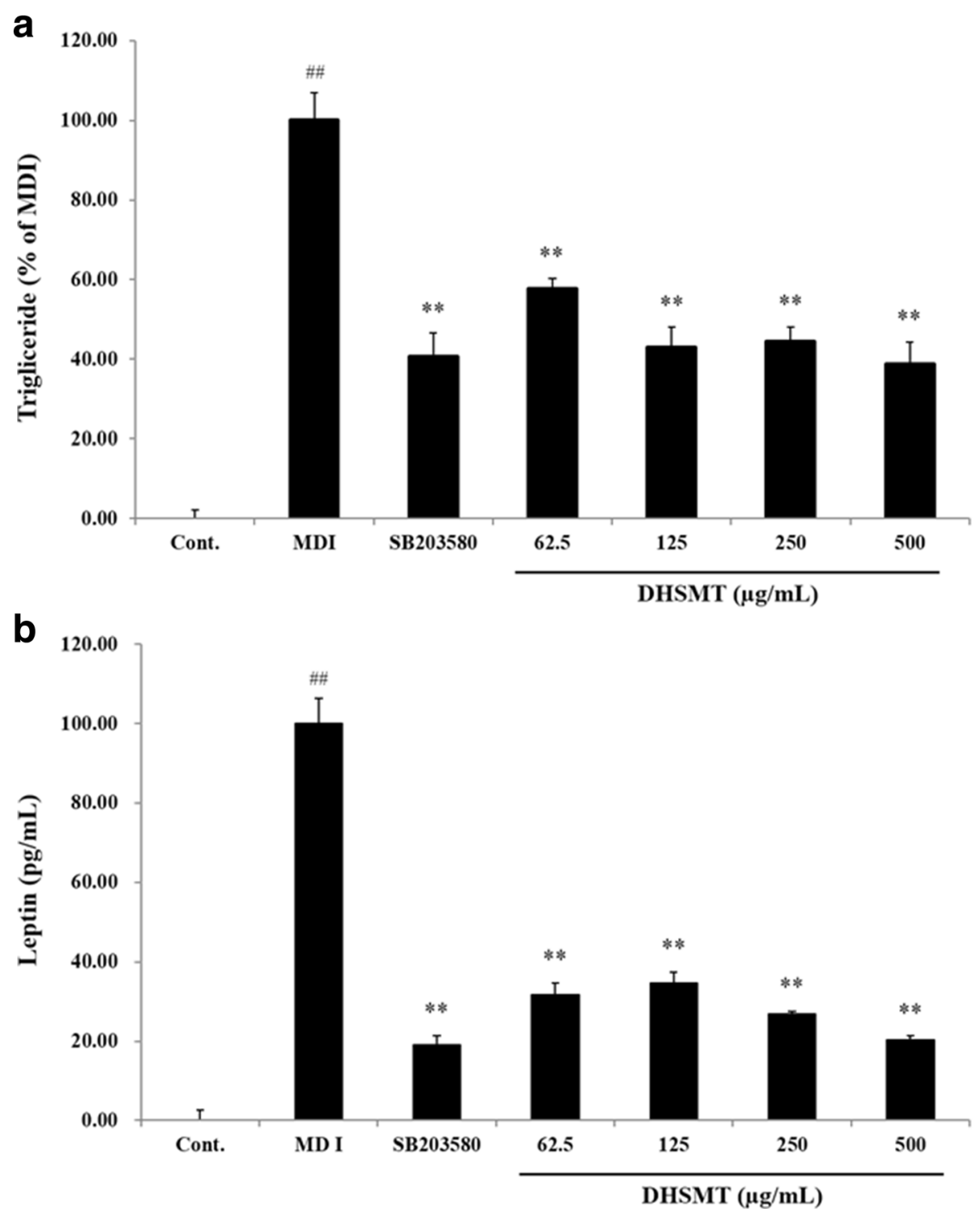

Fig. 4 Inhibitory effect of DHSMT on triglyceride (TG) and leptin accumulation in 3T3-L1 adipocytes. 3T3-L1 preadipocytes were differentiated into adipocytes by using a mixture of 3-isobutyl-1-methylisobutylxanthine, dexamethasone and insulin (MDI) with various concentrations of DHSMT (0, $62.5,125,250$ and $500 \mu \mathrm{g} / \mathrm{ml}$ ) and SB203580 for 7 days. a TG content was measured enzymatically by using TG assay kit (Bioassay Systems, CA, USA). $\mathbf{b}$ Leptin production was measured at $450 \mathrm{~nm}$ by using a mouse leptin immunoassay kit (R\&D Systems). The data are mean values of three experiments \pm SEM; \#\# $<0.01$ compared with control, ${ }^{*} P<0.05$; ${ }^{* *} P<0.01$ compared with the MDI

$277.99 \pm 9.77 \mu \mathrm{g} / \mathrm{mL}$ at DHSMT concentrations of 62.5 , 125, 250 and $500 \mu \mathrm{g} / \mathrm{mL}$, respectively ( $p<0.01$ vs. MDI; Fig. 5a). The concentrations of resistin were $80.44 \pm$ $1.25 \mu \mathrm{g} / \mathrm{mL}, 61.61 \pm 8.05 \mu \mathrm{g} / \mathrm{mL}, 61.04 \pm 5.13 \mu \mathrm{g} / \mathrm{mL}$ and $34.36 \pm 1.26 \mu \mathrm{g} / \mathrm{mL}$ at DHSMT concentrations of 62.5 , 125,250 and $500 \mu \mathrm{g} / \mathrm{mL}$, respectively ( $p<0.01$ vs. MDI; Fig. 5b). The concentrations of PAI-1 were $73.62 \pm$ $9.25 \mu \mathrm{g} / \mathrm{mL}, 53.82 \pm 6.13 \mu \mathrm{g} / \mathrm{mL}, 46.77 \pm 1.95 \mu \mathrm{g} / \mathrm{mL}$ and $37.58 \pm 1.95 \mu \mathrm{g} / \mathrm{mL}$ at DHSMT concentrations of 62.5 , 125, 250 and $500 \mu \mathrm{g} / \mathrm{mL}$, respectively (Fig. 5c). The positive control SB203580, also suppressed the release of adiponectin, resistin and PAI-1 ( $p<0.01$ vs. MDI). We also confirmed that DHSMT at $500 \mu \mathrm{g} / \mathrm{mL}$ decreased the levels of adiponectin, resistin and PAI-1 more than SB203580.

Effect of DHSMT on the expression of adipocyte-specific transcription factors during adipogenesis

Adipogenesis is accompanied by the activation of various adipogenic transcription factors and adipocyte-specific genes. To elucidate the mechanism of inhibition of adipogenesis by DHSMT, differentiated cells were treated with various 

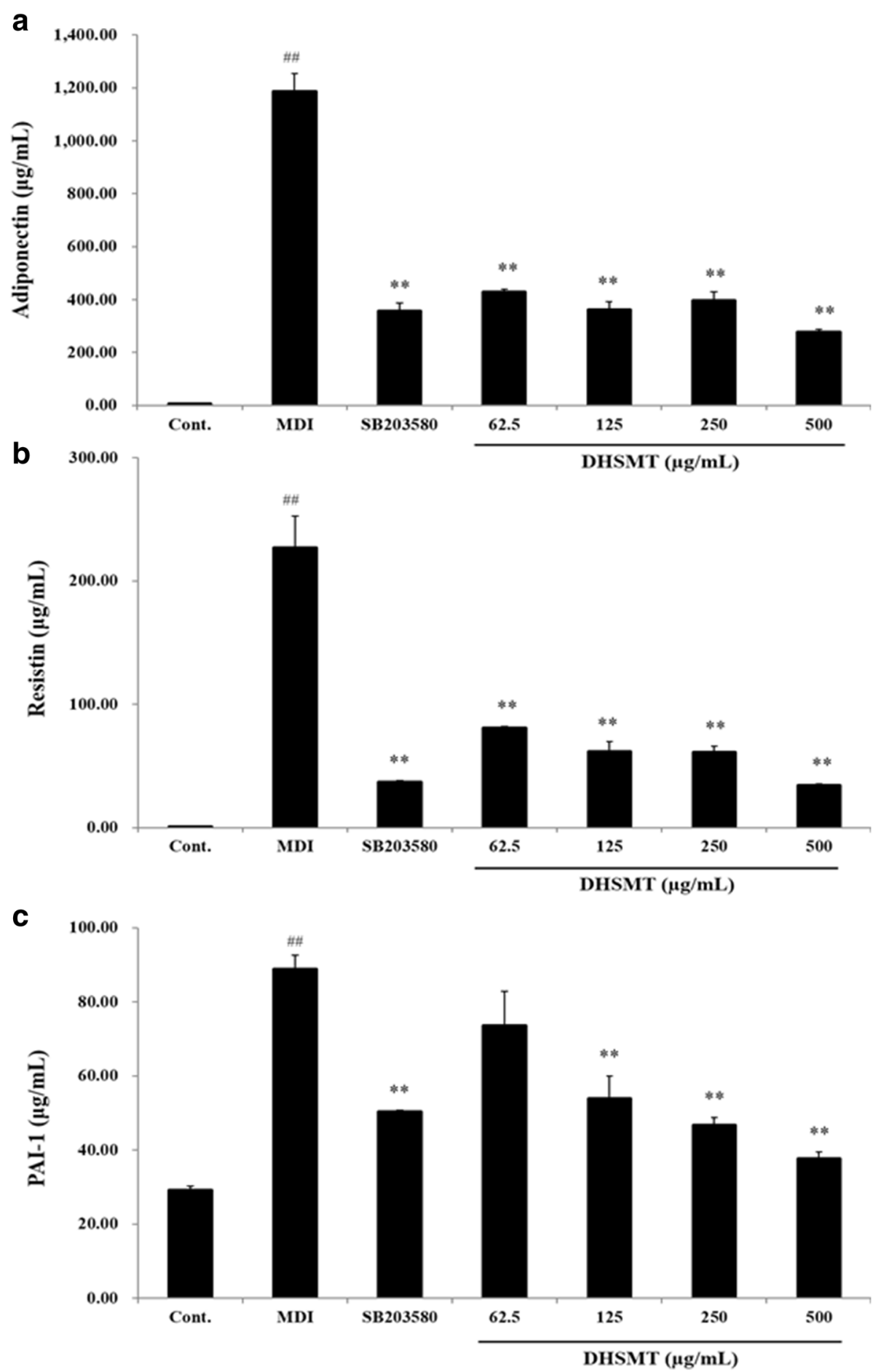

Fig. 5 Inhibitory effect of DHSMT on adipokines accumulation in 3T3-L1 adipocytes. 3T3-L1 preadipocytes were differentiated into adipocytes by various concentrations of $\operatorname{DHSMT}(0,62.5,125,250$ and $500 \mu \mathrm{g} / \mathrm{ml})$ and SB203580 with a mixture of 3-isobutyl-1-methylisobutylxanthine, dexamethasone and insulin (MDI) for 7 days. Adiponectin (a), resistin (b) and PAl-1(c) production were measured by a Milliplex ${ }^{\bullet}$ MAP mouse adipocyte magnetic bead panel kit (Millipore Co. USA). The data are mean values of three experiments \pm SEM; \#\#<0.01 compared with control, ${ }^{*} P<0.05 ;{ }^{*} P<0.01$ compared with the MDI 
concentrations of DHSMT. The protein expression of adipocyte-specific transcriptional factors were analyzed by western blotting. As shown in Fig. 6, DHSMT significantly suppressed adipocyte-specific markers, such as PPAR $\gamma, \mathrm{C} /$ EBP $\alpha$ and FABP4. Notably, the decrease in PPAR $\gamma$ and $\mathrm{C} /$ EBP $\alpha$ expression was dose-dependent. We also found that $500 \mu \mathrm{g} / \mathrm{mL}$ DHSMT dramatically reduced the protein expression of FABP4.

\section{Discussion}

BSS, called eohyul in Korea and yuxue in China, refers to the blood circulation is stagnant or blood flow is not smooth. The classical concepts of BSS were recorded as "blood and vessel stasis", "retained blood" and "vascular obstruction" [5, 16]. BSS may also be related to the following conditions: disturbance in blood circulation and microcirculation, dysfunction of endothelial cells, metabolic disorder, and inflammation [17]. In recent decades, there have been many clinical studies correlating BSS and MS, including atherosclerosis, obesity, hypertension, coronary artery lesions, cardiac function, lipidemia, and diabetes mellitus [18-20].

Obesity, a metabolic disorder, significantly increases the risk of MS with its associated risk factors, such as atherosclerotic cardiovascular disease, diabetes, dyslipidemia, hypertension and other health problems [3, 21, 22].

In the present study, we evaluated the anti-adipogenic efficacy of a water extract of the traditional herbal formula DHSMT in MDI-induced 3T3-L1 adipocytes.

HPLC analysis is conveniently and widely methods to identify constituents of herbal plants in TKM [23]. We analyzed five main components of DHSMT using HPLC. The five main components were as follow: nodakenin from Angelis gigantis radix, ferulic acid from Rehmanniae radix, sophoricoside and safflomin A from Carthami flos, and quercetin from Cnidii rhizome. The established HPLC analysis method will be helpful for improving the quality control of DHSMT.

Oil Red O staining and the TG assay were used to determine whether DHSMT could alter TG production during adipogenesis. Our data revealed that lipid droplets containing TG were markedly increased in adipocytes. But, DHSMT significantly decreased the morphological differentiation of preadipocytes and TG accumulation in adipocytes without cytotoxicity.

Adipokines such as leptin, adiponectin, resistin and PAI-1 are physiologically active cytokines secreted from adipocytes that play an important role in the pathogenesis of MS through inflammation associated with obesity, atherosclerosis and diabetes [24-26].

Leptin secreted by adipocytes suppresses food intake and stimulates energy expenditure and its levels are increased with adipogenesis and obesity [27, 28]. Moreover, intra- and extra-cellular levels of leptin are closely associated with adipocyte size, body fat mass and body weight, and it influenced by environmental factors or hormones such as insulin and DEX [29].

Adiponectin, also known as GBP28, apM1, Acrp30, or AdipoQ, is a 244-residue protein that is produced mainly by white adipose tissue (WAT) and plays an important role in maintaining energy homeostasis and insulin sensitivity [30]. It is induced by transcription factors such as

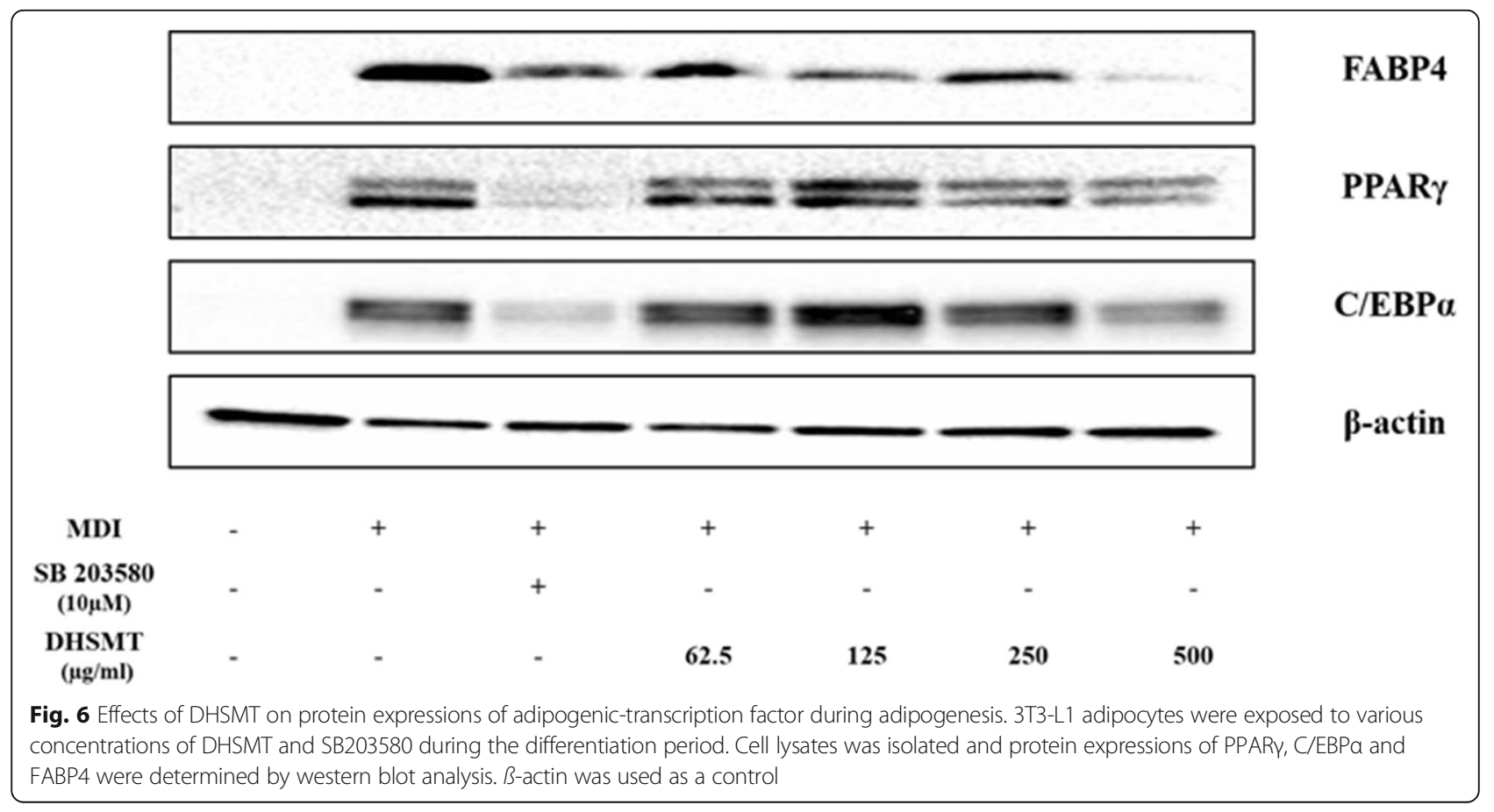


PPAR $\gamma, \mathrm{C} / \mathrm{EBP} \alpha$ and sterol regulatory element-binding protein 1c (SREBP-1c), which are involved in adipocyte differentiation [31]. Furthermore, adiponectin is induced by PPARY agonists and regulates adipocyte differentiation through the PPAR response element [32, 33].

Resistin, an adipose tissue-specific secretory factor in rodents, is a cysteine-rich protein secreted from differentiated adipocytes and WAT [34, 35]. Previous studies have shown that circulating resistin levels are correlated with risk factor of MS such as type 2 diabetes mellitus, obesity, and rheumatoid arthritis [36, 37].

PAI-1, an inhibitor of fibrinolysis, is a serine protease inhibitor that generally inhibits tissue and urokinasetype plasminogen activators. It is upregulated with lipid accumulation and it has been reported that circulating PAI-1 is a risk factor of cardiovascular diseases, obesity, and type 2 diabetes mellitus [38-41].

In this study, the levels of adipokines such as leptin, adiponectin, resistin and PAI-1 markedly decreased following DHSMT treatment. These results suggest that DHSMT may function as a negative regulator of adipogenesis.

Adipocyte differentiation is a process that is regulated by the complex modulation of various transcription factors and extracellular proteins. The transcription factors PPARY and members of the C/EBPs, which regulate adipogenesis and insulin sensitivity in adipocytes, are especially important $[42,43]$. The activation of C/EBP $\beta$ and C/ EBPS, which are expressed earlier than both PPAR $\gamma$ and $\mathrm{C} / \mathrm{EBP} \alpha$ during early adipocyte differentiation, stimulates the expression of C/EBP $\alpha$ and PPAR $\gamma$ either singly or together [44]. Notably, PPAR $\gamma$, one of the nuclear hormone receptors, has been shown to be necessary for adipogenesis. It is extensively stimulated in adipose tissue and stimulates the differentiation of preadipocytes to adipocytes [45]. It is also known to bind to the C/EBP $\alpha$ promoter region, which is regulated by $\mathrm{C} / \mathrm{EBP} \beta$ during adipocyte differentiation [46]. Moreover, transcriptional factors such as PPAR $\gamma$ and $\mathrm{C} / \mathrm{EBP} \alpha$, regulate adipogenesis-specific genes, such as fatty acid synthase (FAS), fatty acid binding protein (FABP) and lipoprotein lipase (LPL) that is involved in maintaining adipogenesis [47]. Also, adipocyte differentiation that is modulated by adipogenic-specific transcription factors markedly increased the expression of termination markers such as adiponectin which can facilitate lipid accumulation during the late adipocyte differentiation stage [48]. Our results revealed that DHSMT considerably down-regulated the protein expression of PPAR $\gamma, \mathrm{C} / \mathrm{EBP} \alpha$ and FABP4, which are essential for adipocyte differentiation and adipogenesis. Moreover, SB203580 as a positive control also significantly suppressed the protein expression of PPAR $\gamma, \mathrm{C} / \mathrm{EBP} \alpha$ and FABP4. These results suggested that DHSMT and SB203580 significantly blocked adipocyte differentiation and lipid accumulation by suppressing adipogenic gene expression.

\section{Conclusions}

In conclusion, results of our present study demonstrate that DHSMT has the inhibitory effects on adipogenesis in 3T3-L1 adipocytes by decreasing the accumulation of intracellular lipid and adipokines such as leptin, adiponectin, resistin and PAI-1 without any cytotoxicity. Furthermore, these anti-adipogenic effects of DHSMT may be mediated through the down-regulation of PPAR $\gamma, \mathrm{C} / \mathrm{EBP} \alpha$ and FABP4 at the protein level. These findings suggest that DHSMT could be used therapeutically for the treatment and prevention of obesity or other MS-associated conditions that are related to BSS.

\section{Abbreviations}

BSS: Blood stasis syndrome; C/EBPa: CCAAT/enhancer binding proteins alpha; CCK-8: Cell counting kit-8; DEX: Dexamethasone; DHSMT: Dohongsamul-

Tang; DMEM: Dulbeco's modified eagle's medium; DMSO: Dimethyl sulfoxide; DPBS: Dulbeco's phosphate-buffered saline; FABP4: Fatty acid binding protein 4; FAS: Fatty acid synthase; FBS: Fetal bovine serum; IBMX: 3-isobutyl1-methylisobutylxanthine; LPL: Lipoprotein lipase; MDI: A mixture of $0.5 \mathrm{mM}$ IBMX, 1 uM dexamethasone and $1 \mu \mathrm{g} / \mathrm{ml}$ insulin; MS: Metabolic syndrome; NBCS: Newborn calf serum; P\&S: Penicillin-streptomycin; PAl-1: Plasminogen activator inhibitor-1; PPARY: Proliferator-activated receptor gamma; SREBP-

1c: Sterol regulatory element-binding protein 1c; TG: Trigliceride;

TKM: Traditional Korean medicine

\section{Acknowledgements}

This research was supported by grants (K17040 and K15110) from Korea Institute of Oriental Medicine (KIOM), Republic of Korea.

\section{Funding}

This research was supported by grants (K17040 and K15110) from Korea Institute of Oriental Medicine (KIOM), Republic of Korea.

\section{Availability of data and materials}

The datasets supporting the conclusions of this article are included within the article.

\section{Authors' contributions}

EHS, HL and SY participated in the design of the study and manuscript preparation. EHS performed experiments. All authors read and approved the final manuscript.

Ethics approval and consent to participate

Not applicable.

Consent for publication

Not applicable.

\section{Competing interests}

The authors declare that they have no competing interests.

\section{Publisher's Note}

Springer Nature remains neutral with regard to jurisdictional claims in published maps and institutional affiliations.

\section{Author details}

${ }^{1}$ KM Fundamental Research Division, Korea Institute of Oriental Medicine 483 Expo-ro, Yuseong-gu, Daejeon 305-811, Republic of Korea. ${ }^{2}$ Clinical Research Division, Korea Institute of Oriental Medicine 483 Expo-ro, Yuseong-gu, Daejeon 305-811, Republic of Korea. 
Received: 20 July 2017 Accepted: 28 November 2017 Published online: 19 December 2017

\section{References}

1. Grundy SM, Barnett JP. Metabolic and health complications of obesity. Dis Mon. 1990;36(12):641-731.

2. Rose G. Population distributions of risk and disease. Nutr Metab Cardiovasc Dis. 1991;1:37-40.

3. Kopelman PG. Obesity as a medical problem. Nature. 2000;404(6778):635-43.

4. Yanovski SZ, Yanovski JA. Obesity. N Engl J Med. 2002;346(8):591-602.

5. Li SM, Xu H, Chen KJ. The diagnostic criteria of blood-stasis syndrome: considerations for standardization of pattern identification. Chin J Integr Med. 2014:20:483-9.

6. Zhou XQ, Liang H, Sun X, Zhou HT. Correlation between TCM blood stasis pattern of coronary heart disease and coronary angiography result: a metaanalysis. Chin. J Evid Based Med. 2012;12(12):1470-7.

7. JI W, Zhou J, Wang S, Ji Z. Logistic regression analysis of relevance between different blood stasis syndromes and related factors in angina pectoris patients. Chin Arch Tradit Chin Med. 2013;7:40

8. Liu X, Guo C, Ma X, Tian R, Zhang Y, Yin H. Relationship between serum estrogen levels and blood stasis syndrome in postmenopausal women with coronary heart disease. Pak J Med Sci. 2015;31(1):25-30.

9. Yoon YG. Dohaejeongbo. Seoul: Eui Seing Dang Publ; 2007. p. 9-15.

10. Jeong $W Y$, Jeon $\mathrm{BH}$. Influence of medicinal herbal drug on the experimental model of thrombosis in animal. Korean J Oriental Pathol. 1996;10(1):72-8.

11. Jeong HY, Cho YL. The effect of DohongSamulTang(DST) on immunesystem in L1210 cells-transplanted mice. Korean J Oriental Pathol. 1999; 13(1):132-40.

12. You BS, Jung JE, Park JY, Yun JM, Lee I, Moon BS. Protective effects of dohongsamul-tang on zinc-mediated cytotoxicity in $\mathrm{H} 9 \mathrm{c} 2$ cardiomyoblast cell. Korean J Oriental Physiol Pathol. 2004:18(5):1374-81.

13. Chang SH, Lim EM, Lee E. Effects of Dohongsamul-tang on surgically induced endometriosis in rats. J Korean. Obstet Gynecol. 2006;19(1):125-35.

14. Engelman JA, Lisanti MP, Scherer PE. Specific inhibitors of p38 mitogenactivated protein kinase block 3T3-L1 adipogenesis. J Biol Chem. 1998, 273(48):32111-20.

15. He Q, Huang C, Zhao L, Feng J, Shi Q, Wang D, Wang S. a-Naphthoflavone inhibits 3T3-L1 pre-adipocytes differentiation via modulating P38MAPK signaling. Int J Clin Exp Pathol. 2013;6(2):168-78.

16. Matsumoto C, Kojima T, Ogawa K, Kamegai S, Oyama T, Shibagaki Y, Kawasaki T, Fujinaga H, Takahashi K, Hikiami H, Goto H, Kiga C, Koizumi K, Sakurai H, Muramoto H, Shimada Y, Yamamoto M, Terasawa K, Takeda S, Saiki I. A proteomic approach for the diagnosis of 'Oketsu'(blood stasis), a pathophysiologic concept of Japanese traditional (Kampo) medicine. Evid Based Complement Alternat Med. 2008;5(4):463-74.

17. Chen KJ. Blood stasis syndrome and its treatment with activating blood circulation to remove blood stasis therapy. Chin J Integr Med. 2012; 18(12):891-6.

18. Yu X, Zhang $L, X u H$. Progress in research on relevant factors affecting TCM syndrome differentiation of CHD. Chin J Int Med Cardio/Cerebrovasc Dis. 2009;7(5):581-4

19. Zhu YB, Wang Q, CY W, Pang GM, Zhao JX, Shen SL, Xia ZY, Yan X. Logistic regression analysis on relationships between traditional Chinese medicine constitutional types and overweight or obesity. Chin J Integr Med. 2010; 8(11):1023-8.

20. Lu Y, Li T. Effect of Chinese drugs for activating blood circulation and removing blood stasis on carotid atherosclerosis and ischemic cerebrovascular events. Zhongguo Zhong Xi Yi Jie He Za Zhi. 2014; 34(3):303-7.

21. Reaven G. Metabolic syndrome: pathophysiology and implications for management of cardiovascular disease. Circ. 2002:106(3):286-8.

22. Eckel RH, Grundy SM, Zimmet PZ. The metabolic syndrome. Lancet. 2005; 365(9468):1415-28

23. Zhang $H$, Shen $P$, Cheng $Y$. Identification and determination of the major constituents in traditional Chinese medicine Si-Wu-tang by HPLC coupled with DAD and ESI-MS. J Pharm Biomed Anal. 2004:34(3):705-13.

24. Gong H, Ni Y, Guo X, Fei L, Pan X, Guo M, Chen R. Resistin promotes 3T3-L1 preadipocyte differentiation. Eur J Endocrinol. 2004;150(6):885-92.

25. Fu Y, Luo N, Klein RL, Garvey WT. Adiponectin promotes adipocyte differentiation, insulin sensitivity, and lipid accumulation. J Lipid Res. 2005; 46(7):1369-79.
26. Liang X, Kanjanabuch T, Mao SL, Hao CM, Tang YW, Declerck PJ, Hasty AH, Wasserman DH, Fogo AB, Ma $\sqcup$. Plasminogen activator inhibitor-1 modulates adipocyte differentiation. Am J Physiol Endocrinol Metab. 2006;290(1):E103-13.

27. Yuan G, Jia J, Di L, Zhou L, Dong S, Ye J, Wang D, Yang L, Wang J, Li L, Yang Y, Mao C, Chen M. Effects of C-reactive protein on adipokines genes expression in 3T3-L1 adipocytes. Biochem Biophys Res Commun. 2012;424(3):462-8.

28. Alvala R, Alvala M, Sama V, Dharmarajan S, Ullas JV, Reddy M. Scientific evidence for traditional claim of anti-obesity activity of Tecomella undulata bark. J Ethnopharmacol. 2013;148(2):441-8.

29. Houseknecht KL, Baile CA, Matteri RL, Spurlock ME. The biology of leptin: a review. J Anim Sci. 1998;76(5):1405-20.

30. DK O, Ciaraldi T, Henry RR. Adiponectin in health and disease. Diabetes Obes Metab. 2007;9(3):282-9.

31. Guo L, Li X, Tang QQ. Transcriptional regulation of adipocyte differentiation: a central role for CCAAT/enhancer-binding protein (C/EBP) $\beta$. J Biol Chem. 2015;290(2):755-61.

32. Maeda N, Takahashi M, Funahashi T, Kihara S, Nishizawa H, Kishida K, Nagaretani H, Matsuda M, Komuro R, Ouchi N, Kuriyama H, Hotta K, Nakamura T, Shimomura I, Matsuzawa Y. PPARy ligands increase expression and plasma concentrations of adiponectin, an adipose-derived protein. Diabetes. 2001;50(9):2094-9.

33. Kadowaki T, Yamauchi T. Adiponectin and adiponectin receptors. Endocr Rev. 2005;26(3):439-51

34. Kim KH, Lee K, Moon YS, Sul HS. A cysteine-rich adipose tissue-specific secretory factor inhibits adipocyte differentiation. J Biol Chem. 2001;276(14):11252-6.

35. Steppan CM, Bailey ST, Bhat S, Brown EJ, Banerjee RR, Wright CM, Patel HR, Ahima RS, Lazar MA. The hormone resistin links obesity to diabetes. Nature. 2001:409(6818):307-12

36. Savage DB, Sewter CP, Klenk ES, Segal DG, Vidal-Puig A, Considine RV, O'Rahilly S. Resistin/Fizz3 expression in relation to obesity and peroxisome proliferatoractivated receptor- $\gamma$ action in humans. Diabetes. 2001;50(10):2199-202.

37. Senolt L, Housa D, Vernerova Z, Jirásek T, Svobodová R, Veigl D, Anderlová K, Müller-Ladner U, Pavelka K, Haluzík M. Resistin in rheumatoid arthritis synovial tissue, synovial fluid and serum. Ann Rheum Dis. 2007;66(4):458-63.

38. Hoekstra T, Geleijnse JM, Schouten EG, Kluft C. Plasminogen activator inhibitor-type 1: its plasma determinants and relation with cardiovascular risk. Thromb Haemost. 2004:91(5):861-72.

39. Ma L, Mao SL, Taylor KL, Kanjanabuch T, Guan Y, Zhang Y, Brown NJ, Swift LL, McGuinness OP, Wasserman DH, Vaughan DE, Fogo AB. Prevention of obesity and insulin resistance in mice lacking plasminogen activator inhibitor 1. Diabetes. 2004;53(2):336-46.

40. Mathieu P, Lemieux I, Després JP. Obesity, inflammation, and cardiovascular risk. Clin Pharmacol Ther. 2010;87(4):407-16

41. Conde J, Scotece M, Gómez R, López V, Gómez-Reino Jل Lago F, Gualillo O. Adipokines: biofactors from white adipose tissue. A complex hub among inflammation, metabolism, and immunity. Biofactors. 2011;37(6):413-20.

42. Darlington GJ, Ross SE, MacDougald OA. The role of C/EBP genes in adipocyte differentiation. J Biol Chem. 1998;273(46):30057-60.

43. Rosen ED, Hsu CH, Wang X, Sakai S, Freeman MW, Gonzalez FJ, Spiegelman BM. C/EBPa induces adipogenesis through PPARy: a unified pathway. Genes Dev. 2002;16(1):22-6.

44. Wu Z, Rosen ED, Brun R, Hauser S, Adelmant G, Troy AE, McKeon C, Darlington GJ, Spiegelman BM. Cross-regulation of C/EBPa and PPARY controls the transcriptional pathway of adipogenesis and insulin sensitivity. Mol Cell. 1999:3(2):151-8.

45. Schoonjans K, Staels B, Auwerx J. The peroxisome proliferator activated receptors (PPARS) and their effects on lipid metabolism and adipocyte differentiation. Biochim Biophys Acta. 1996;1302(2):93-109.

46. Hou Y, Xue P, Bai Y, Liu D, Woods CG, Yarborough K, Fu J, Zhang O, Sun G, Collins S, Chan JY, Yamamoto M, Andersen ME, Pi J. Nuclear factor erythroidderived factor 2-related factor 2 regulates transcription of CCAAT/enhancerbinding protein $\beta$ during adipogenesis. Free Radic Biol Med. 2012;52(2):462-72.

47. Zhang Y, Fan S, Hu N, Gu M, Chu C, Li Y, Lu X, Huang C. Rhein reduces fat weight in $\mathrm{db} / \mathrm{db}$ mouse and prevents diet-induced obesity in C57BI/6 mouse through the inhibition of PPARy signaling. PPAR Res. 2012; https:// doi.org/10.1155/2012/374936

48. MacDougald OA, Lane MD. Transcriptional regulation of gene expression during adipocyte differentiation. Annu Rev Biochem. 1995;64(1):345-73. 